\title{
Large-scale association analysis of TNF/LTA gene region polymorphisms in type 2 diabetes
}

\author{
Vesna Boraska*1, Nigel W Rayner2, Christopher J Groves³, Timothy M Frayling ${ }^{4}$, Mahamadou Diakite2, Kirk A Rockett², \\ Dominic P Kwiatkowski2,5, Aaron G Day-Williams5, Mark I McCarthy2,3 and Eleftheria Zeggini2,5
}

\begin{abstract}
Background: The TNF/LTA locus has been a long-standing T2D candidate gene. Several studies have examined association of TNF/LTA SNPs with T2D but the majority have been small-scale and produced no convincing evidence of association. The purpose of this study is to examine T2D association of tag SNPs in the TNF/LTA region capturing the majority of common variation in a large-scale sample set of UK/Irish origin.

Methods: This study comprised a case-control (1520 cases and 2570 control samples) and a family-based component (423 parent-offspring trios). Eleven tag SNPs (rs928815, rs909253, rs746868, rs1041981 (T60N), rs1800750, rs1800629 (G308A), rs361525 (G-238A), rs3093662, rs3093664, rs3093665, and rs3093668) were selected across the TNF/LTA locus and genotyped using a fluorescence-based competitive allele specific assay. Quality control of the obtained genotypes was performed prior to single- and multi-point association analyses under the additive model.

Results: We did not find any consistent SNP associations with T2D in the case-control or family-based datasets.

Conclusions: The present study, designed to analyse a set of tag SNPs specifically selected to capture the majority of common variation in the TNF/LTA gene region, found no robust evidence for association with T2D. To investigate the presence of smaller effects of TNF/LTA gene variation with T2D, a large-scale meta-analysis will be required.
\end{abstract}

\section{Background}

Type 2 diabetes (T2D) is a complex disease influenced by environmental and genetic factors. Genetic association studies have thus far identified at least 20 replicating T2D susceptibility loci of modest to small effect, which together explain less than $10 \%$ of the genetic component of disease [1,2]. Several genome-wide association scans (GWAS) have been carried out for T2D [3-10]. These have used a variety of genotyping platforms with different SNP content, typically capturing over $80 \%$ of common variation in European-descent populations. Although this extent of coverage, in combination with imputation approaches [11], reduces the need for candidate gene studies, in-depth investigation of variation at loci of interest can conceivably prove useful in characterising them further.

The TNF/LTA locus has been a long-standing T2D candidate gene. T2D and obesity have been hypothesised to

\footnotetext{
* Correspondence: vboraska@mefst.hr

1 Department of Medical Biology, University of Split School of Medicine, Split, Croatia

Full list of author information is available at the end of the article
}

have an inflammatory basis [12,13]. Insulin resistance is associated with increased plasma levels of proinflammatory cytokines such as TNF and IL6, and with interactions between TNF and NFkappaB that lead to an increase of oxidative stress [14-16].

The genes coding for TNF and LTA reside in the class III MHC region on chromosome 6p21.3. TNF and LTA are members of the TNF ligand superfamily, bind the same TNF receptors and mediate similar pleiotropic effects $[17,18]$. Of the multiple SNPs in the TNF/LTA gene region, the rs361525 (G-238A) and rs1800629 (G308A) TNF promoter variants, and the rs 1041981 (T60N) LTA variant have been the most frequently studied in T2D. The majority of studies of TNF/LTA SNPs have been small-scale, with some notable exceptions [17], and have produced no convincing evidence for association with the disease [19-27].

The Wellcome Trust Case Control Consortium (WTCCC) T2D GWAS examined 17 directly typed and imputed SNPs from the TNF/LTA gene region and detected no association with T2D in 2000 cases and 3000 
controls from the UK $[6,28]$. In addition, a GWAS metaanalysis for T2D carried out by the DIAGRAM consortium, which examined the same 17 directly genotyped and imputed SNPs in the TNF/LTA region in samples from three sources (Diabetes Genetics Initiative (DGI), Finland-United States Investigation of NIDDM Genetics (FUSION) and WTCCC) also found no association between TNF/LTA SNPs and T2D [28]. However, the WTCCC genotyping platform (Affymetrix 500k) and HapMap-based imputation do not provide exhaustive coverage of common variation in this gene region. To increase coverage, we carried out a genetic association study of the TNF/LTA loci in a total of 5359 samples from the UK by typing additional SNPs, selected on the basis of sequence data to better capture variation in the region.

\section{Methods \\ Subjects}

This study comprised a case-control and a family-based component. The case-control dataset included 1520 cases from the Diabetes UK Warren 2 Sib Pair Repository (61.5\% males) and 2570 control samples from the 1958 British birth cohort ( $\mathrm{n}=2027,50.6 \%$ males) [29], and the HRC control collection ( $\mathrm{n}=543,49.9 \%$ males) derived from UK blood donors and available from the European Centre for Cell Culture (ECACC, CAMR, Salisbury, UK). The family-based dataset comprised 423 parent-offspring trios (58.5\% male probands) from the Diabetes UK Warren 2 Trios (W2T) Repository. W2T probands were selected by strict clinical, immunological and genetic criteria as previously described [30]. All cases included in the present study had T2D diagnosed according to the World Health Organization criteria and were selected for early diabetes onset and/or positive family history. Importantly, autoimmune diabetes was excluded based on GAD antibody typing, age of disease onset above 25, insulin independence following diagnosis, no ketoacedosis and no first degree relatives with type 1 diabetes $[30,31]$. Clinical characteristics of the cases are provided in Table $1.58 .2 \%$ of WTCCC cases and 35.3\% of WTCCC controls overlapped with the samples examined as part of our study. All subjects were exclusively of UK/Irish origin and provided signed informed consent prior to blood sampling. Reported investigations have been carried out following the principles of the Declaration of Helsinki as revised in 2000. Ethical oversight for collection and use of the T2D cases was provided from MREC 00/6/55, Peterborough and Fenland LREC 05/Q0106/78 and from over 100 individual local research ethics committee approvals. Use of the 1958 Birth Cohort samples is in accordance with Joint UCL/UCLH Research Ethics Committee A approval 08/H0714/40 and South-East Multi-Centre Research Ethics Committee approval MREC 01/1/44. The HRC samples are a commercially available set of anonymised DNA samples from blood donors sourced from the Health Protection Agency Culture Collection and approved for research use only.

\section{SNP Selection and Genotyping}

Eleven haplotype-tagging SNPs (tag SNPs) (rs928815, rs909253, rs746868, rs1041981 (T60N), rs1800750, rs1800629 (G-308A), rs361525 (G-238A), rs3093662, rs3093664, rs3093665, rs3093668) were selected across the TNF and LTA loci from sequencing and genotype data generated in 32 Caucasian trios as previously described [32,33] (Table 2). Genotypes for this study were determined using a fluorescence-based competitive allele specific assay (Kaspar, Kbioscience, UK). Genotyping and SNP selection details are available from the authors on request. When we investigated linkage disequilibrium (LD) between the SNPs, we found SNPs rs928815 and rs746868, and SNPs rs909253 and rs1041981 to be in tight LD with each other $\left(\mathrm{r}^{2}>0.8\right)$. SNP pairs $\mathrm{rs} 361525-$ rs3093662, rs361525-rs3093668 and rs3093662rs3093664 displayed moderate LD $\left(0.6<\mathrm{r}^{2}<0.8\right)$, while all other investigated SNPs showed no or very weak pairwise LD $\left(0<\mathrm{r}^{2}<0.52\right)$ (Additional file 1, Figures S1a and S1b). Eight of the 11 studied tag SNPs have been genotyped in the HapMap (rs928815, rs909253, rs1041981, rs1800750, rs1800629, rs3093662, rs3093665, rs3093668). These 8 variants capture $61.1 \%$ of common (MAF > 0.05) variation across the TNF/LTA gene region (overall 18 SNPs in the HapMap database) at an $\mathrm{r}^{2}$ threshold of $\geq 0.8$, based on the HapMap (CEU population, Rel 24/PhaseII Nov 08 [34]). The proportion of common variation across the region captured by the typed tag SNPs was calculated

Table 1: Clinical characteristics of T2D cases

\begin{tabular}{lccccc}
\hline Cohort & Female & Male & Average Age At Study (years) & Average AODc (years) & Average BMI (kg/m2) \\
\hline W2Ca & 583 & 932 & 60.23 & 51.46 & 31.80 \\
\hline W2Tb & 173 & 249 & 46.26 & 40.44 & 32.91 \\
\hline aW2C - Warren 2 Cohort; ${ }^{b}$ W2T - Warren 2 Trios probands; cAOD - Age of diagnosis &
\end{tabular}

aW2C - Warren 2 Cohort; ${ }^{b}$ W2T - Warren 2 Trios probands; ${ }^{~ A O D ~-~ A g e ~ o f ~ d i a g n o s i s ~}$ 
Table 2: Characteristics of 11 TNF/LTA tag SNPs.

\begin{tabular}{|c|c|c|c|c|c|}
\hline dbSNP rs number & Position on chr. 6a & Alternative name & Gene location & Alleles (C:M)b & dbSNP CEU MAFc \\
\hline rs928815 & 31639194 & / & $5^{\prime} L T A$ & G:T & 0.383 \\
\hline rs909253 & 31648292 & $252 \mathrm{G}>\mathrm{A}$ & LTA-intron 1 & $\mathrm{~T}: \mathrm{C}$ & 0.358 \\
\hline rs746868 & 31648408 & / & LTA-intron 1 & $\mathrm{G}: \mathrm{C}$ & 0.405 \\
\hline rs1041981 & 31648763 & Thr26Asn;T60N; 804C > A & LTA-exon 3 & $\mathrm{C}: \mathrm{A}$ & 0.358 \\
\hline rs1800750 & 31650942 & $-376 \mathrm{G}>\mathrm{A}$ & $5^{\prime}$ of $T N F$ & $\mathrm{G}: \mathrm{A}$ & 0.008 \\
\hline rs1800629 & 31651010 & $-308 G>A$ & $5^{\prime}$ of $T N F$ & $A: G$ & 0.217 \\
\hline rs361525 & 31651080 & $-238 G>A$ & $5^{\prime}$ of $T N F$ & $\mathrm{G}: \mathrm{A}$ & 0.068 \\
\hline rs3093662 & 31652168 & IVS1-122A > G; +851 & TNF-intron 1 & $A: G$ & 0.071 \\
\hline rs3093664 & 31652621 & / & TNF-intron 3 & $A: G$ & 0.065 \\
\hline rs3093665 & 31653370 & / & TNF - 3'UTR & $A: C$ & 0.017 \\
\hline rs3093668 & 31654474 & / & $3^{\prime}$ of $T N F$ & $\mathrm{G}: \mathrm{C}$ & 0.042 \\
\hline
\end{tabular}

on a multimarker tagging basis using Tagger [35]. However, this is an underestimate of the capture of common variation, since the 3 remaining non-HapMap variants were excluded from this calculation. To asses coverage further we performed another calculation on the basis of the 1000 genomes project data (http://www.1000 genomes.org) April 2009 release).

\section{Statistical analysis}

Quality control (QC) of the obtained genotypes was performed prior to association analysis. The SNP genotyping success rates ranged from $93.3 \%$ to $98.6 \%$. We evaluated the comparative rate of missing genotypes between cases and controls using Plink (version 1.00) [36] and excluded rs3093662 from the case-control association analysis due to low call rate. The tag SNPs were tested for deviation from Hardy-Weinberg equilibrium (HWE) in affected and healthy individuals separately using Stata v. 8 (Stata Corporation, College Station, TX, USA) and Plink (version 1.00) [36]. No deviations from HWE were observed. Minor allele frequencies (MAFs) of controls in both studies were compared with the National Center for Biotechnology Information SNP database (NCBI dbSNP) MAFs for the CEU population and showed no significant differences. Testing of Mendelian inheritance using Plink and
Haploview [36,37] identified inconsistencies in one family, which was excluded from further analysis. After QC, 10 tag SNPs were taken forward to case-control association analyses and 11 tag SNPs were included in familybased association analysis.

Single-point case-control association analyses were carried out using Stata v. 8 (Stata Corporation, College Station, TX, USA). Multi-point case-control association analyses of fixed haplotype sizes (sliding windows of 2-10 SNPs shifting 1 SNP at a time) were performed using the expectation-maximisation algorithm-based approach implemented in Plink [36]. Single-point and multi-point (sliding windows of 2-11 SNPs) family-based association analyses were carried out using implementations of the transmission disequilibrium test (TDT) in Plink [36]. 10,000 permutations were run for each association analysis. $\mathrm{r}^{2}$ and $\mathrm{D}^{\prime}$ measures of pairwise LD were calculated for all SNPs using Haploview [37]. Power was calculated under the log-additive model for a range of effect-sizes $(1.1<\mathrm{OR}>2)$ at $\alpha=0.05$ using Quanto [38]. All association analyses are unadjusted (e.g. for BMI, blood pressure and other environmental variables), as these data were not available to us. We did not investigate gene-environment interactions. 


\section{Results}

Genotype distributions for the 11 TNF/LTA tag SNPs in the case-control and parent-offspring datasets are shown in Additional file 1, Table S1 and Table S2, respectively. Overall, we did not identify any consistent significant SNP associations with disease. The most frequently studied SNPs, rs1800629 (G-308A), rs361525 (G-238A), and rs1041981 (T60N) did not show robust association with the disease in any dataset (Table 3). Exhaustive multimarker case-control analyses did not identify any strong haplotypic associations (data not shown). There were no statistically significant deviations in the transmission of alleles from parents to affected probands by single-point (Table 4) or haplotype-based analysis (data not shown). Our study had $80 \%$ power at $\alpha=0.05$ to identify modest/ large effect sizes (OR > 1.3) at common loci (Additional file 1, Tables S3a and S3b).

In the WTCCC GWAS [5,28], a total number of 17 (one directly genotyped, rs1799964, and 16 imputed) SNPs from the TNF/LTA gene region were investigated and showed no association with T2D. The case-control association results of the most frequently studied SNPs, rs1800629 (G-308A), rs361525 (G-238A) and rs1041981 $(\mathrm{T} 60 \mathrm{~N})$ from the present study and from the WTCCC dataset (across which there is considerable overlap) is shown in Table 5. Five of the tag SNPs from the present

Table 3: Case-control association analysis results for the 10 TNF/LTA tag SNPs

\begin{tabular}{|c|c|c|c|c|}
\hline SNP & OR allele & OR $^{\mathbf{a}}$ & $95 \% \mathrm{Cla}^{\mathrm{a}}$ & p value \\
\hline rs928815 & $\mathrm{T}$ & 1.056 & $0.96-1.16$ & 0.255 \\
\hline rs909253 & $\mathrm{T}$ & 0.889 & $0.81-0.98$ & 0.015 \\
\hline rs746868 & $\mathrm{C}$ & 1.066 & $0.97-1.17$ & 0.18 \\
\hline rs1041981 (T60N) & $C$ & 0.892 & $0.81-0.98$ & 0.019 \\
\hline rs1800750 & $A$ & 1.001 & $0.64-1.54$ & 0.996 \\
\hline rs1800629 (G-308A) & A & 0.984 & $0.88-1.11$ & 0.791 \\
\hline rs361525 (G-238A) & G & 0.981 & $0.81-1.19$ & 0.845 \\
\hline rs3093664 & $A$ & 0.996 & $0.85-1.17$ & 0.958 \\
\hline rs3093665 & $C$ & 1.192 & $0.86-1.64$ & 0.268 \\
\hline rs3093668 & $\mathrm{C}$ & 1.053 & $0.85-1.3$ & 0.625 \\
\hline
\end{tabular}

aallelic OR and $95 \%$ confidence intervals. study (rs746868, rs1800750, rs361525, rs3093664 and rs3093665) were not directly typed or imputed in the WTCCC GWAS. To assess the extent of additional coverage these 5 SNPs offer, we examined LD based on our genotype data in T2D cases and controls. SNPs rs746868 and rs361525 are in high $\mathrm{LD}\left(\mathrm{r}^{2}=0.99\right.$ and $\left.\mathrm{r}^{2}=0.79\right)$ with two of the WTCCC-typed SNPs, rs928815 and rs3093668 respectively. The remaining $3 \mathrm{SNPs}$ that have not been examined in the WTCCC (rs1800750, rs3093664 and rs3093665) demonstrate low LD with WTCCC-typed and other HapMap SNPs $\left(0<\mathrm{r}^{2}<0.52\right)$ (Additional file 1, Figures S1a and S1b). Therefore these polymorphisms capture additional variation missed by the WTCCC study.

We investigated capture further on the basis of the 1000 genomes project data. Four of our 11 tag SNPs (rs909253, rs1800750, rs3093662 and rs3093665) were not found in the 1000G dataset and the remaining 7 tag SNPs capture $60.6 \%$ of common variation (overall 33 TNF/LTA SNPs in the $1000 \mathrm{G}$ dataset) on a multimarker tagging basis at an $\mathrm{r}^{2}$ threshold of $\geq 0.8$. This is again an underestimate of the TNF/LTA common variation capture by our tag SNPs.

\section{Discussion}

In this study of 11 tag SNPs, we find no consistent evidence for association between TNF/LTA region variation and T2D. The present study was designed to analyse a set of tag SNPs specifically selected to capture the majority of common variation in the TNF/LTA gene region based on proprietary sequence and genotype data [32,33]. Although a proportion of the investigated variants had been examined as part of the WTCCC GWAS $[5,28]$, this study provides further capture of common variation across the region. However, the overall conclusion remains unchanged - there was no evidence of association with disease.

This is one of the largest studies to date, showing no association between TNF/LTA variation and T2D. A recent meta-analysis (2106 cases and 2920 controls) of the rs361525 (G-238A) variant did not detect a significant association with T2D [23]. Similar meta-analyses of all reported association studies for the rs1800629 (G-308A) and rs1041981 (T60N) SNPs, which have been widely investigated with respect to T2D, may boost power to detect possible small effects at these loci.

T2D is a complex disease caused by complex interplay between environmental and genetic factors. A limitation of our study is that we have not been able to adjust for or investigate interaction of SNPs with BMI, age, gender, blood pressure, serum lipid levels etc. as these data were unavailable to us. In addition, even though our study examined the majority of common variation across the region, it is possible that causal, associated variants may have been missed. 
Table 4: Transmission disequilibrium analysis of 11 TNF/LTA tag SNPs in T2D parent-offspring trios

\begin{tabular}{|c|c|c|c|c|c|c|c|}
\hline SNP & $\mathbf{N a}$ & $A 1: A 2^{b}$ & MAFc & $T: U^{d}$ & ORe & $95 \% \mathrm{Cl} f$ & p value \\
\hline rs928815 & 322 & $\mathrm{~T}: \mathrm{G}$ & 0.359 & 132:165 & 0.8 & $0.64-1.01$ & 0.055 \\
\hline rs909253 & 321 & $C: T$ & 0.358 & $157: 145$ & 1.083 & $0.86-1.36$ & 0.489 \\
\hline rs746868 & 324 & C:G & 0.362 & $135: 163$ & 0.828 & $0.66-1.04$ & 0.104 \\
\hline rs1041981 (T60N) & 301 & $A: C$ & 0.355 & $146: 138$ & 1.058 & $0.84-1.34$ & 0.635 \\
\hline rs1800750 & 327 & $A: G$ & 0.012 & $7: 12$ & 0.583 & $0.23-1.48$ & 0.251 \\
\hline rs1800629 (G-308A) & 237 & G:A & 0.195 & $73: 70$ & 1.043 & $0.75-1.45$ & 0.801 \\
\hline rs361525 (G-238A) & 324 & $A: G$ & 0.055 & $35: 35$ & 1 & $0.63-1.59$ & 1 \\
\hline rs3093662 & 321 & $\mathrm{G}: \mathrm{A}$ & 0.079 & $47: 44$ & 1.068 & $0.71-1.61$ & 0.753 \\
\hline rs3093664 & 321 & G:A & 0.086 & $55: 43$ & 1.279 & $0.86-1.91$ & 0.225 \\
\hline rs3093665 & 324 & $C: A$ & 0.023 & $14: 12$ & 1.167 & $0.54-2.52$ & 0.694 \\
\hline rs3093668 & 321 & C:G & 0.045 & $31: 22$ & 1.409 & $0.82-2.43$ & 0.216 \\
\hline
\end{tabular}

a $\mathrm{N}$ - number of informative trios; ${ }^{\mathrm{b}} \mathrm{A} 1: \mathrm{A} 2$ - minor allele $v s$. major allele; $\mathrm{CMAF}$ - minor allele frequency in affected probands; ${ }^{\mathrm{d}} \mathrm{copies}$ of the minor allele transmitted $(\mathrm{T})$ and untransmitted (U), eodds ratios (OR), f95\% lower and upper confidence intervals.

\section{Conclusions}

The purpose of this study was to examine if genetic variation in the genes encoding inflammatory proteins TNF and LTA alter the risk of developing T2D. We tested a carefully selected set of haplotype tagging SNPs that capture the majority of common variation in the TNF/LTA gene region in case-control and parent-offspring samples and find no robust evidence for association. Large-scale meta-analyses will be required to investigate the presence of smaller effects at polymorphic sites in the TNF/LTA gene region.

Table 5: The comparison of association results for T60N, G-308A and G-238A between the present study and the WTCCC T2D GWAS

\begin{tabular}{|c|c|c|c|c|c|c|c|c|}
\hline SNP & OR allele & OR $^{\mathbf{a}}$ & $95 \% \mathrm{Cl}^{\mathrm{a}}$ & p-value & WTCCC SNPb & OR $^{\mathbf{a}}$ & $95 \% \mathrm{Cl}^{\mathrm{a}}$ & p-value \\
\hline rs1041981 (T60N) & $\mathrm{C}$ & 0.89 & $0.81-0.98$ & 0.02 & rs1041981 & 1.06 & $0.96-1.16$ & 0.67 \\
\hline rs1800629 (G-308A) & A & 0.98 & $0.88-1.11$ & 0.79 & rs1800629 & 1.05 & $0.93-1.19$ & 0.56 \\
\hline rs361525 (G-238A) & G & 0.98 & $0.81-1.19$ & 0.85 & rs3093668 (proxy for rs361525) & 0.86 & $0.71-1.05$ & 0.21 \\
\hline
\end{tabular}

aOR - allelic odds ratio and 95\% confidence intervals; ${ }^{b}$ All three SNPs were imputed in the WTCCC data set. 58.2\% of WTCCC cases and $35.3 \%$ of WTCCC controls overlapped with the samples from our study. 


\section{Additional material}

Additional file 1 Supplementary material. Figure S1a LD relationship $\left(r^{2}\right)$ between the investigated TNF/LTA tag SNPs in the case-control dataset; Fig ure $\mathrm{S} 1 \mathrm{~b} L \mathrm{LD}$ relationship $\left(\mathrm{r}^{2}\right)$ between the investigated TNF/LTA tag SNPs in the parent-offspring dataset; Table S1 Genotype counts of the 10 TNF/LTA tag SNPs passing quality control in the case-control dataset; Table S2 Genotype counts of 11 TNF/LTA tag SNPs in the T2D probands and their parents; Table S3 Power calculations based on each TNF/LTA tag SNPS

\section{Abbreviations}

CEU: central European population; GWAS: genome wide association study; HWE: Hardy-Weinberg equilibrium; LD: linkage disequilibrium; LTA: lymphotoxin alpha; MAF: minor allele frequency; QC: quality control; SNP: single nucleotide polymorphism; tag SNP: tagging SNP; TDT: transmission disequilibrium test; TNF: tumor necrosis factor; T2D: type 2 diabetes mellitus.

\section{Competing interests}

The authors declare that they have no competing interests.

\section{Authors' contributions}

VB carried out statistical analysis, participated in interpretation of results and drafted the manuscript. NWR managed the data files and participated in statistical analyses. CJG directed the genotyping and managed the samples. TMF participated in study design. MD, KAR and DPK contributed sequence data for the TNF/LTA gene region and to manuscript preparation. AGDW contributed to study design, analysis and manuscript preparation. MIM conceived and coordinated the study, participated in study design, interpretation and revised the manuscript. EZ supervised the study and participated in study design, statistical analysis, interpretation, draft and revision of the manuscript. All authors read and approved the final version of the manuscript.

\section{Acknowledgements}

The work was supported by the Diabetes UK RD04/0002809 and RD06/ 0003190 grants. We thank The British Scholarship Trust for support for the VB study visit to Oxford. This study makes use of data generated by the Wellcome Trust Case-Control Consortium. A full list of the investigators who contributed to the generation of the data is available from http://www.wtccc.org.uk. Funding for the project was provided by the Wellcome Trust under award 076113. This work was supported by the Wellcome Trust (WT088885/Z/09/Z). We acknowledge use of DNA from the British 1958 Birth Cohort collection, funded by the UK Medical Research Council grant G0000934 and Wellcome Trust grant 068545/Z/02.

\section{Author Details}

'Department of Medical Biology, University of Split School of Medicine, Split, Croatia, ${ }^{2}$ Wellcome Trust Centre for Human Genetics, University of Oxford, Oxford, UK, ${ }^{3}$ Oxford Centre for Diabetes, Endocrinology and Metabolism, University of Oxford, Oxford, UK, 4Peninsula Medical School, University of Exeter, Exeter, UK and ${ }^{5}$ Wellcome Trust Sanger Institute, Wellcome Trust Genome Campus, Hinxton, Cambridge, UK

Received: 27 November 2009 Accepted: 6 May 2010 Published: 6 May 2010

\section{References}

1. McCarthy MI, Zeggini E: Genome-wide association studies in type 2 diabetes. Current diabetes reports 2009, 9(2):164-171.

2. Rung J, Cauchi S, Albrechtsen A, Shen L, Rocheleau G, Cavalcanti-Proenca C, Bacot F, Balkau B, Belisle A, Borch-Johnsen K, et al: Genetic variant near IRS1 is associated with type 2 diabetes, insulin resistance and hyperinsulinemia. Nature genetics 2009, 41(10):1110-1115.

3. Saxena R, Voight BF, Lyssenko V, Burtt NP, de Bakker PI, Chen H, Roix JJ, Kathiresan S, Hirschhorn JN, Daly MJ, et al:: Genome-wide association analysis identifies loci for type 2 diabetes and triglyceride levels. Science (New York, NY) 2007, 316(5829):1331-1336.

4. Scott LJ, Mohlke KL, Bonnycastle LL, Willer CJ, Li Y, Duren WL, Erdos MR, Stringham HM, Chines PS, Jackson AU, et al:: A genome-wide association study of type 2 diabetes in Finns detects multiple susceptibility variants. Science (New York, NY) 2007, 316(5829):1341-1345.
5. Genome-wide association study of 14,000 cases of seven common diseases and 3,000 shared controls. Nature 2007, 447(7145):661-678.

6. Zeggini E, Weedon MN, Lindgren CM, Frayling TM, Elliott KS, Lango H, Timpson NJ, Perry JR, Rayner NW, Freathy RM, et al:: Replication of genome-wide association signals in UK samples reveals risk loci for type 2 diabetes. Science (New York, NY) 2007, 316(5829):1336-1341.

7. Sladek R, Rocheleau G, Rung J, Dina C, Shen L, Serre D, Boutin P, Vincent D, Belisle A, Hadjadj S, et al:: A genome-wide association study identifies novel risk loci for type 2 diabetes. Nature 2007, 445(7130):881-885.

8. Salonen JT, Uimari P, Aalto JM, Pirskanen M, Kaikkonen J, Todorova B, Hypponen J, Korhonen VP, Asikainen J, Devine C, et al.: Type 2 diabetes whole-genome association study in four populations: the DiaGen consortium. American journal of human genetics 2007, 81(2):338-345.

9. Steinthorsdottir V, Thorleifsson G, Reynisdottir I, Benediktsson R, Jonsdottir T, Walters GB, Styrkarsdottir U, Gretarsdottir S, Emilsson V, Ghosh S, et al:: A variant in CDKAL1 influences insulin response and risk of type 2 diabetes. Nature genetics 2007, 39(6):770-775.

10. Unoki H, Takahashi A, Kawaguchi T, Hara K, Horikoshi M, Andersen G, Ng DP, Holmkvist J, Borch-Johnsen K, Jorgensen T, et al.: SNPs in KCNQ1 are associated with susceptibility to type 2 diabetes in East Asian and European populations. Nature genetics 2008, 40(9):1098-1102.

11. Marchini J, Howie B, Myers S, McVean G, Donnelly P: A new multipoint method for genome-wide association studies by imputation of genotypes. Nature genetics 2007, 39(7):906-913.

12. Dandona P, Aljada A, Bandyopadhyay A: Inflammation: the link between insulin resistance, obesity and diabetes. Trends in immunology 2004, 25(1):4-7.

13. Pickup JC, Crook MA: Is type II diabetes mellitus a disease of the innate immune system? Diabetologia 1998, 41(10):1241-1248.

14. Plomgaard P, Nielsen AR, Fischer CP, Mortensen OH, Broholm C, Penkowa M, Krogh-Madsen R, Erikstrup C, Lindegaard B, Petersen AM, et al: Associations between insulin resistance and TNF-alpha in plasma skeletal muscle and adipose tissue in humans with and without type 2 diabetes. Diabetologia 2007, 50(12):2562-2571.

15. Hotamisligil GS, Shargill NS, Spiegelman BM: Adipose expression of tumor necrosis factor-alpha: direct role in obesity-linked insulin resistance. Science (New York, NY) 1993, 259(5091):87-91.

16. Yang J, Park Y, Zhang H, Xu X, Laine GA, Dellsperger KC, Zhang C: Feedforward signaling of TNF-alpha and NF-kappaB via IKK-beta pathway contributes to insulin resistance and coronary arteriolar dysfunction in type 2 diabetic mice. American journal of physiology 2009, 296(6):H1850-1858.

17. Zeggini E, Groves CJ, Parkinson JR, Halford S, Owen KR, Frayling TM, Walker M, Hitman GA, Levy JC, O'Rahilly S, et al: Large-scale studies of the association between variation at the TNF/LTA locus and susceptibility to type 2 diabetes. Diabetologia 2005, 48(10):2013-2017.

18. Feugeas JP, Caillens H, Poirier JC, Charron D, Marcelli-Barge A, Wautier JL: Influence of metabolic and genetic factors on tumour necrosis factoralpha and lymphotoxin-alpha production in insulin-dependent diabetes mellitus. Diabetes \& metabolism 1997, 23(4):295-301.

19. Susa S, Daimon M, Sakabe J, Sato H, Oizumi T, Karasawa S, Wada K, Jimbu Y, Kameda W, Emi M, et al:: A functional polymorphism of the TNF-alpha gene that is associated with type $2 \mathrm{DM}$. Biochemical and biophysical research communications 2008, 369(3):943-947.

20. Nicaud V, Raoux S, Poirier O, Cambien F, O'Reilly DS, Tiret L: The TNF alpha/G-308A polymorphism influences insulin sensitivity in offspring of patients with coronary heart disease: the European Atherosclerosis Research Study II. Atherosclerosis 2002, 161(2):317-325

21. Li H, Groop L, Nilsson A, Weng J, Tuomi T: A combination of human leukocyte antigen $\mathrm{DQB} 1{ }^{*} 02$ and the tumor necrosis factor alpha promoter G308A polymorphism predisposes to an insulin-deficient phenotype in patients with type 2 diabetes. The Journal of clinical endocrinology and metabolism 2003, 88(6):2767-2774.

22. Heijmans BT, Westendorp RG, Droog S, Kluft C, Knook DL, Slagboom PE: Association of the tumour necrosis factor alpha $-308 \mathrm{G} / \mathrm{A}$ polymorphism with the risk of diabetes in an elderly population-based cohort. Genes and immunity 2002, 3(4):225-228.

23. Feng $R$, Li Y, Zhao D, Wang C, Niu Y, Sun C: Lack of association between TNF $238 \mathrm{G} / \mathrm{A}$ polymorphism and type 2 diabetes: a meta-analysis. Acta diabetologica 2009, 46(4):339-343.

24. Willer CJ, Bonnycastle LL, Conneely KN, Duren WL, Jackson AU, Scott LJ, Narisu N, Chines PS, Skol A, Stringham HM, et al.: Screening of 134 single 
nucleotide polymorphisms (SNPs) previously associated with type 2 diabetes replicates association with 12 SNPs in nine genes. Diabetes 2007, 56(1):256-264

25. Ozaki K, Ohnishi Y, lida A, Sekine A, Yamada R, Tsunoda T, Sato H, Sato H, Hori M, Nakamura Y, et al:: Functional SNPs in the lymphotoxin-alpha gene that are associated with susceptibility to myocardial infarction. Nature genetics 2002, 32(4):650-654.

26. Hamid YH, Urhammer SA, Glumer C, Borch-Johnsen K, Jorgensen T, Hansen T, Pedersen O: The common T60N polymorphism of the lymphotoxin-alpha gene is associated with type 2 diabetes and other phenotypes of the metabolic syndrome. Diabetologia 2005, 48(3):445-451.

27. Yamada A, Ichihara S, Murase Y, Kato T, Izawa H, Nagata K, Murohara T, Yamada Y, Yokota M: Lack of association of polymorphisms of the lymphotoxin alpha gene with myocardial infarction in Japanese. Journal of molecular medicine (Berlin, Germany) 2004, 82(7):477-483.

28. Zeggini E, Scott $\sqcup$, Saxena R, Voight BF, Marchini JL, Hu T, de Bakker PI, Abecasis GR, Almgren P, Andersen G, et al:: Meta-analysis of genomewide association data and large-scale replication identifies additional susceptibility loci for type 2 diabetes. Nature genetics 2008, 40(5):638-645

29. Power C, Elliott J: Cohort profile: 1958 British birth cohort (National Child Development Study). International journal of epidemiology 2006, 35(1):34-41.

30. Frayling TM, Walker M, McCarthy MI, Evans JC, Allen LI, Lynn S, Ayres S, Millauer B, Turner C, Turner RC, et al:: Parent-offspring trios: a resource to facilitate the identification of type 2 diabetes genes. Diabetes 1999, 48(12):2475-2479

31. Wiltshire S, Hattersley AT, Hitman GA, Walker M, Levy JC, Sampson M, O'Rahilly S, Frayling TM, Bell II, Lathrop GM, et al:: A genomewide scan for loci predisposing to type 2 diabetes in a U.K. population (the Diabetes UK Warren 2 Repository): analysis of 573 pedigrees provides independent replication of a susceptibility locus on chromosome 1q. American journal of human genetics 2001, 69(3):553-569.

32. Hanchard N, Diakite M, Koch O, Keating B, Pinder M, Jallow M, Sisay-Joof F, Nijnik A, Wilson J, Udalova I, et al.: Implications of inter-population linkage disequilibrium patterns on the approach to a disease association study in the human MHC class III. Immunogenetics 2006 , 58(5-6):465-470

33. Hanchard N, Rockett K, Udalova I, Wilson J, Keating B, Koch O, Nijnik A, Diakite M, Herbert M, Kwiatkowski D: An investigation of transmission ratio distortion in the central region of the human MHC. Genes and immunity 2006, 7(1):51-58

34. The International HapMap Project. Nature 2003, 426(6968):789-796.

35. de Bakker PI, Yelensky R, Pe'er I, Gabriel SB, Daly MJ, Altshuler D: Efficiency and power in genetic association studies. Nature genetics 2005, 37(11):1217-1223

36. Purcell S, Neale B, Todd-Brown K, Thomas L, Ferreira MA, Bender D, Maller J, Sklar P, de Bakker PI, Daly MJ, et al:: PLINK: a tool set for whole-genome association and population-based linkage analyses. American journal of human genetics 2007, 81(3):559-575.

37. Barrett JC, Fry B, Maller J, Daly MJ: Haploview: analysis and visualization of LD and haplotype maps. Bioinformatics (Oxford, England) 2005, 21(2):263-265

38. Gauderman WJ: Candidate gene association analysis for a quantitative trait, using parent-offspring trios. Genetic epidemiology 2003, 25(4):327-338.

\section{Pre-publication history}

The pre-publication history for this paper can be accessed here: http://www.biomedcentral.com/1471-2350/11/69/prepub

\section{doi: 10.1186/1471-2350-11-69}

Cite this article as: Boraska et al., Large-scale association analysis of TNF/LTA gene region polymorphisms in type 2 diabetes BMC Medical Genetics 2010, 11:69

\section{Submit your next manuscript to BioMed Central} and take full advantage of:

- Convenient online submission

- Thorough peer review

- No space constraints or color figure charges

- Immediate publication on acceptance

- Inclusion in PubMed, CAS, Scopus and Google Scholar

- Research which is freely available for redistribution 